Dental, Oral and Craniofacial Research

\title{
Material selection for CAD/CAM dentistry: Glass ceramic or hybrid materials?
}

\author{
Hao Yu* \\ Department of Prosthodontics, Fujian Medical University, PR China
}

Over the past few years, nonmetallic (metal-free) computeraided design/computer-aided manufacturing (CAD/CAM) materials, including ceramics and composites, have been widely used in dentistry [1]. Given that both materials have unfavorable properties related to the longevity of the restoration, the resin-ceramic hybrid materials are introduced to include the positive characteristics of ceramics and composites and to overcome their disadvantages [2]. Currently, two types of hybrid materials are available in dentistry: polymerinfiltrated ceramic network (PICN) materials (e.g., Vita Enamic) and materials with dispersed fillers (e.g., GC CeraSmart, 3M Lava Ultimate Restorative, and Shofu Block HC) [2]. The hybrid materials have an elasticity modulus closer to that of dentin and the property of absorbing masticatory forces, which can be particularly valuable for implant-supported restorations [2]. Additionally, the hybrid materials may be more easily fabricated and repaired than ceramics [3]. Regarding adhesive bonding to the hybrid materials, the literature seems to reach a consensus that the combination of mechanical conditioning and chemical conditioning prior to bonding yields the highest bond strength of the hybrid materials [4,5]. More specifically, well-established mechanical conditioning (e.g., alumina air abrasion for materials with dispersed fillers and hydrofluoric acid etching for PICN materials) followed by silanization could be beneficial for the long-term bond strength. However, due to the relative novelty of the hybrid materials, the author is unaware of any standard bonding protocols in the literature. Moreover, the manufacturer (3M ESPE) recently withdrew the crown indication for Lava Ultimate Restorative because of a reportedly high debonding rate. Moreover, although the hybrid materials can be stained and glazed, they still could not achieve the esthetic quality of veneered ceramic restorations, especially when a poly-chromatic restoration is needed.

The hybrid materials are claimed to cover the indications of onlays, inlays, and crowns. Moreover, they have been recommended for occlusal rehabilitation [6]. However, there are only limited in vivo data regarding the clinical performance of the hybrid materials. Lu, et al. [7] reported that the survival rates for Vita Enamic and Vitablocs Mark II were 97.0\% and $90.7 \%$ after 3 years, respectively $(P>.05)$. After an observation time of 3 years, the survival rates were $97.4 \%$ for inlays and $95.6 \%$ for partial coverage restoration made with Vita Enamic [8]. Although the PICN restorations showed a favorable clinical performance over a short-term observation, long-term clinical data are needed to confirm this finding.

Based on the current scientific evidence, it may be concluded that the novel hybrid materials exhibit a similar mechanical behavior to that of human tooth. Compared with the ceramics, the use of hybrid materials may reduce the fracture rate due to the flexibility. In general, the hybrid materials are properly indicated for posterior onlays and inlays in a single appointment, while the laminate veneers, crowns, and bridges made of the ceramics are still the best options.

\section{References}

1. Ruse ND, Sadoun MJ (2014) Resin-composite blocks for dental CAD/CAM applications. J Dent Res 93: 1232-1234. [Crossref]

2. Mainjot AK, Dupont NM, Oudkerk JC, Dewael TY, Sadoun MJ (2016) From artisanal to CAD-CAM blocks: State of the art of indirect composites. J Dent Res 95: 487-495. [Crossref]

3. van Noort R (2012) The future of dental devices is digital. Dent Mater 28: 3-12. [Crossref]

4. Cekic-Nagas I, Ergun G, Egilmez F, Vallittu PK, Lassila LV (2016) Micro-shear bond strength of different resin cements to ceramic/glass-polymer CAD-CAM block materials. J Prosthodont Res 60: 265-273. [Crossref]

5. El-Damanhoury HM, Gaintantzopoulou MD (2018) Self-etching ceramic primer versus hydrofluoric acid etching: Etching efficacy and bonding performance. J Prosthodont Res 62: 75-83. [Crossref]

6. Edelhoff D, Liebermann A, Beuer F, Stimmelmayr M, Güth JF (2016) Minimally invasive treatment options in fixed prosthodontics. Quintessence Int 47: 207-216. [Crossref]

7. Lu T, Peng L, Xiong F, Lin XY, Zhang P, Lin ZT, Wu BL (2018) A 3-year clinical evaluation of endodontically treated posterior teeth restored with two different materials using the CEREC AC chair-side system. J Prosthet Dent 119: 363-368. [Crossref]

8. Spitznagel FA, Scholz KJ, Strub JR, Vach K, Gierthmuehlen PC (2018) Polymerinfiltrated ceramic $\mathrm{CAD} / \mathrm{CAM}$ inlays and partial coverage restorations: 3-year results of a prospective clinical study over 5 years. Clin Oral Investig 22: 1973-1983. [Crossref]
Copyright: (C2018 Yu H. This is an open-access article distributed under the terms of the Creative Commons Attribution License, which permits unrestricted use, distribution, and reproduction in any medium, provided the original author and source are credited.
${ }^{\star}$ Correspondence to: Hao Yu, Department of Prosthodontics, Fujian Medical University, PR China, E-mail: haoyu-cn@hotmail.com

Received: November 26, 2018; Accepted: November 28, 2018; Published: November 30, 2018 